\title{
Kapasitas Fungsi Intelektual pada Berbagai Kelompok Interaksi Sosial Anak Autis
}

\author{
Raddi Moekdas, Abdurachman Sukadi, Tetty Yuniati \\ Bagian Ilmu Kesehatan Anak \\ Fakultas Kedokteran Universitas Padjadjaran \\ Rumah Sakit Hasan Sadikin, Bandung
}

\begin{abstract}
Abstrak
Autis dikelompokkan berdasarkan interaksi sosial dan kapasitas fungsi intelektual. Penelitian ini bertujuan untuk mengetahui hubungan antara kelompok interaksi sosial dan kapasitas fungsi intelektual. Penelitian dilakukan Januari-Maret 2007 pada anak autis di pusat terapi Our Dream dan Indigrow Bandung dengan rancangan hybride selective prevalence. Anak autis dikelompokkan berdasarkan interaksi sosial serta kapasitas fungsi intelektual. Usia dan riwayat terapi perilaku merupakan faktor perancu kelompok interaksi sosial. Uji statistik pada penelitian ini menggunakan Kruskall-Wallis dan Kolmogorov-Smirnov dua populasi. Subjek penelitian yang memenuhi kriteria inklusi berjumlah 99 anak. Kelompok aloof, pasif, aktif tetapi aneh masing-masing sebanyak dua, 31, dan 66 anak autis. Kapasitas fungsi intelektual rendah sebanyak 70 dan tinggi 29 anak autis. Usia $\leq 5$ dan $>5$ tahun ditemukan pada 58 dan 41 anak autis (pKW=0,453). Riwayat pernah dan belum pernah mendapat terapi perilaku ditemukan pada 37 dan 62 anak autis (pKS =1,00). Didapatkan 70 anak $(71 \%)$ memiliki kapasitas fungsi intelektual rendah dan 29 anak (29\%) dengan kapasitas fungsi intelektual tinggi. Kelompok interaksi sosial berhubungan bermakna dengan kapasitas fungsi intelektual anak autis $(\mathrm{p}=0,04)$. Disimpulkan bahwa kelompok interaksi sosial aloof, pasif dan aktif tetapi aneh berhubungan dengan kapasitas fungsi intelektual rendah dan tinggi. [MKB. 2010;42(3):96-100].
\end{abstract}

Kata kunci: Autis, kapasitas fungsi intelektual, kelompok interaksi sosial

\section{Intellectual Functioning in Social Interaction Subgroups of Autism Children}

\begin{abstract}
Autism classified based on social interaction and intellectual functioning. Aim of this study was to find out the association between social interaction and intellectual functioning. This hybride selective prevalence design study was conducted from January-March 2007 on autism children admitted to therapy center of Our Dream and Indigrow, Bandung. Subjects were classified based on social interaction and intellectual functioning. Age and history of behavior therapy were confounding factors. Data was analyzed using Kruskall-Wallis and two-sample Kolmogorov-Smirnov test. Subjects who fulfilled the inclusion criteria were 99 autism children. Subgroups aloof, passive, and active but odd were two, 31, 66 children, respectively. Low and high functioning were found in 70 and 29 children. Age of $\leq 5$ and $>5$ years were found in 58 and 41 children ( $\mathrm{pKW}=0.453$ ). Classification of behavioral therapy were 37 and 62 children ( $\mathrm{pKS}=1.00)$. The association of social interaction with intellectual functioning autism showed significant value 0.04. In conclusion, this study showed association of social interaction aloof, passive, and active but odd with low and high intellectual functioning. [MKB. 2010;42(3):96-100].
\end{abstract}

Key words: Autism, intellectual functioning, social interaction subgroups

Korespondensi: dr. Raddi Moekdas, Bagian Ilmu Kesehatan Anak, Fakultas Kedokteran Universitas Padjadjaran, Rumah Sakit Hasan Sadikin, jalan Pasteur 38 Bandung 40161, telepon (022) 2034426, mobile 08122250030,

e-mail:ma_rindi@yahoo.co.id 


\section{Pendahuluan}

Prevalensi autis dilaporkan meningkat dengan cepat dalam 20-30 tahun terakhir, ${ }^{1,2}$ sedangkan di Indonesia belum terdapat angka yang tepat karena belum ada penelitian yang mendalam. ${ }^{3,4}$

Autis adalah kelainan perkembangan yang ditandai gangguan bahasa verbal dan nonverbal, gangguan interaksi sosial, keterbatasan aktivitas dan perhatian, serta perilaku stereotipik. ${ }^{1,2}$ Autis sering disertai dengan penyakit penyerta lain (komorbid). Adanya komorbid tersebut akan mempengaruhi kapasitas fungsi intelektual, respons terapi, dan luaran jangka panjang., ${ }^{1,5,6}$

Autis merupakan spectrum disorder, berarti gejala klinis dan derajat berat ringannya kelainan bervariasi. ${ }^{7}$ Pola, variasi, dan beratnya gejala yang timbul akan mempengaruhi kapasitas fungsi intelektual, kemampuan bahasa verbal dan nonverbal, ${ }^{8}$ interaksi sosial dengan anak lain serta kemampuan komunikasi. ${ }^{7}$ Pengelompokan autis berdasarkan kemampuan interaksi sosial dibagi menjadi kelompok aloof, pasif, dan aktif tetapi aneh. Pengelompokan autis berdasarkan kapasitas fungsi intelektual dibagi menjadi tiga kelompok yaitu rendah, sedang dan tinggi. ${ }^{3,-11}$ Tingkat kapasitas fungsi intelektual merupakan prediktor penting luaran jangka panjang pada anak autis. ${ }^{12,13}$

Hubungan kapasitas fungsi intelektual dengan etiologi dan ekspresi gejala autis masih belum jelas. ${ }^{6-8}$ Demikian pula tingkat kapasitas fungsi intelektual dan perbedaan profil kemampuan bahasa verbal dan nonverbal berhubungan dengan petanda etiologi atau subgrup berbeda pada anak autis masih dalam perdebatan. ${ }^{8}$ Penelitian Tager Flusberg dan Joseph ${ }^{14}$ memperlihatkan perbedaan profil kemampuan bahasa verbal dan nonverbal yang berpengaruh terhadap perbedaan aspek komunikasi dan interaksi sosial anak autis.

Kapasitas fungsi intelektual yang rendah berhubungan dengan onset usia dini, kumpulan gejala klinis kompleks, dan gangguan bahasa yang berat. ${ }^{1,11,12,15}$ Walaupun anak autis menunjukkan pola kelainan perilaku serta derajat kelainan yang beragam, beberapa penelitian menunjukkan perbedaan profil kemampuan bahasa verbal dan nonverbal, berkomunikasi, serta interaksi sosial anak autis pada kelompok usia prasekolah dan sekolah. $^{7,8,16,17}$

Penelitian ini dilakukan untuk mengetahui hubungan antara kelompok interaksi sosial dan kapasitas fungsi intelektual anak autis .

\section{Metode}

Penelitian dilakukan bulan Januari-Maret 2007 di Pusat Terapi Kelainan Perkembangan dan Saraf Anak, yaitu Our Dream dan Indigrow Children Development and Autism Center Bandung dengan rancangan hybride selective prevalence. Subjek penelitian adalah seluruh anak autis yang tercatat di Our Dream dari Januari 2004 sampai Maret 2007 dan Indigrow Children Development and Autism Center dari Januari 2005 sampai Maret 2007. Anak autis yang disertai dengan epilepsi, catatan medis tidak lengkap, dan jenis kelamin perempuan dikeluarkan dari penelitian.

Diagnosis anak autis ditentukan oleh dokter spesialis anak (neuropediatri) berdasarkan kriteria Diagnostic and Statistical Manual of Mental Disorders Fourth Edition (DSM IV). Usia subjek ditentukan berdasarkan usia pada saat didiagnosis autis. Riwayat terapi perilaku anak autis ditentukan apabila telah mendapat terapi perilaku 40 jam/minggu minimal tiga bulan. Diagnosis epilepsi anak autis berdasarkan bangkitan kejang lebih dari satu kali dan/atau adanya gelombang epileptiform pada electroencephalogram (EEG). Klasifikasi interaksi sosial aloof, pasif, dan aktif tetapi aneh pada anak autis sesuai dengan kriteria Wing. ${ }^{18}$ Tingkat kapasitas fungsi intelektual ditentukan berdasarkan kompleksitas dan derajat berat triad gejala klinis autis yaitu: gangguan bahasa/komunikasi dan interaksi sosial, serta aktivitas/perilaku/minat bersifat stereotipik, ritual, kaku, dan terbatas, disertai dengan satu atau lebih gejala klinis lain yang meliputi imajinasi sosial/imitasi/pretend play, gangguan respons dan motor sensoris, atau adanya kemampuan khusus yang dinilai oleh tim, terdiri dari dokter spesialis saraf anak, psikolog, dan terapis. ${ }^{3,9,11,12}$

Uji statistik hubungan usia dan riwayat terapi perilaku dengan kelompok interaksi sosial aloof, pasif, dan aktif tetapi aneh, masing-masing menggunakan Kruskall-Wallis dan Kolmogorov Smirnov dua populasi. Uji statistik hubungan kelompok interaksi sosial aloof, pasif, dan aktif tetapi aneh dengan kapasitas fungsi intelektual rendah dan tinggi menggunakan Kolmogorov Smirnov dua populasi. Uji statistik data dilakukan dengan menggunakan SPSS 13.0.

Penelitian ini telah mendapatkan persetujuan dari Direktur Medis Pusat Terapi Kelainan Perkembangan dan Saraf Anak, Our Dream dan Indigrow Children Development \& Autism Center 
Tabel 1 Hubungan Kelompok Usia dan Riwayat Terapi Perilaku dengan Kelompok Interaksi Sosial

\begin{tabular}{|c|c|c|c|c|}
\hline \multirow{2}{*}{ Karakteristik } & \multicolumn{3}{|c|}{ Interaksi Sosial } & \multirow[b]{2}{*}{$\mathbf{p}$} \\
\hline & $\operatorname{Aloof}(\mathrm{n}=2)$ & Pasif $(n=31)$ & Aktif tetapi Aneh $(n=66)$ & \\
\hline \multicolumn{5}{|l|}{ Usia (tahun) } \\
\hline$\leq 5$ & $2(100 \%)$ & $17(55 \%)$ & $39(59 \%)$ & \multirow{2}{*}{$0,453 *$} \\
\hline$>5$ & $0(0 \%)$ & $14(45 \%)$ & $27(41 \%)$ & \\
\hline \multicolumn{5}{|c|}{ Riwayat Terapi Perilaku } \\
\hline $\mathrm{Ya}$ & $0(\quad 0 \%)$ & $14(45 \%)$ & $23(35 \%)$ & \multirow{2}{*}{$1,00^{* *}$} \\
\hline Tidak & $2(100 \%)$ & $17(55 \%)$ & $43(65 \%)$ & \\
\hline
\end{tabular}

Tabel 2 Hubungan antara Kelompok Interaksi Sosial dan Kapasitas Fungsi Intelektual

\begin{tabular}{cccc}
\hline Interaksi Sosial & \multicolumn{2}{c}{ Kapasitas Fungsi Intelektual } & Tinggi \\
\hline Aloof $(\mathrm{n}=2)$ & $2(100 \%)$ & $0(0 \%)$ & \\
Pasif $(\mathrm{n}=31)$ & $15(48 \%)$ & $16(52 \%)$ & $0,04 *$ \\
Aktif tetapi Aneh $(\mathrm{n}=66)$ & $53(80 \%)$ & $13(20 \%)$ & \\
\hline *Uji Komogorov Smirnov dua populasi bermakna jika nilai $<<0,05$ & &
\end{tabular}

*Uji Komogorov Smirnov dua populasi bermakna jika nilai $\mathrm{p}<0,05$

Bandung dan Komite Etik Penelitian Kesehatan Fakultas Kedokteran Universitas Padjadjaran.

\section{Hasil}

Jumlah anak autis sebanyak124 orang, terdiri dari 111 laki-laki dan 13 perempuan, dengan rasio $8,5: 1$. Anak autis yang memenuhi kriteria inklusi berjumlah 99 orang $(80 \%)$. Anak autis yang tidak menjadi subjek penelitian terdiri dari 12 laki-laki dengan epilepsi, catatan medis tidak lengkap, berusia $>18$ tahun, dan 13 perempuan.

Subjek penelitian yang termasuk kelompok interaksi sosial aloof, pasif, dan aktif tetapi aneh masing-masing berjumlah dua, 31, dan 66 anak autis. Diagnosis autis pada 99 subjek penelitian ditegakkan pada usia 57,28 $\pm 26,46$ bulan. Dari 99 subjek penelitian, 58 anak berusia $\leq 5$ tahun dan 41 anak $>5$ tahun, 37 anak pernah dan 62 anak belum pernah mendapat terapi perilaku. Pada uji statistik Kruskall-Wallis dan Kolmogorov Smirnov dua populasi didapatkan masing-masing nilai $\mathrm{p}>0,05$ (Tabel 1). Hal ini menunjukkan usia dan riwayat terapi perilaku tidak berhubungan dengan kelompok interaksi sosial aloof, pasif, dan aktif tetapi aneh.

Jumlah subjek penelitian yang termasuk kapasitas fungsi intelektual rendah 70 anak $(71 \%)$, sedang delapan anak (8\%), dan tinggi 21 anak (21\%). Delapan anak autis dengan kapasitas fungsi intelektual sedang dikelompokkan menjadi tinggi berdasarkan persamaan luaran jangka panjang, yaitu dapat hidup bermasyarakat dan mandiri. ${ }^{11}$ Uji statistik Kolmogorov Smirnov dua populasi didapatkan nilai $\mathrm{p}<0,05$. Hasil ini menunjukkan bahwa kelompok interaksi sosial aloof, pasif, dan aktif tetapi aneh berhubungan dengan kapasitas fungsi intelektual rendah dan tinggi anak autis (Tabel 2).

\section{Pembahasan}

Prevalensi dan perbandingan anak autis laki-laki dengan perempuan pada penelitian ini lebih tinggi dibandingkan dengan beberapa penelitian sebelumnya. ${ }^{1,13,15}$ Angka ini tidak dapat dijadikan acuan prevalensi anak autis di Bandung karena data berasal dari dua tempat dan jumlah anak autis yang sebenarnya di Bandung belum diketahui. Angka prevalensi yang tinggi ini mencerminkan bahwa autis bukan lagi kelainan yang jarang ditemukan.

Diagnosis autis ditegakkan pada usia rata-rata $57,28 \pm 26,46$ bulan, Hasil ini sesuai dengan penelitian sebelumnya. ${ }^{10}$ Berdasarkan penelitian ini, diagnosis autis dapat ditegakkan lebih dini yaitu pada usia 17 bulan. Hal ini menunjukkan kemampuan yang baik dalam melakukan skrining dan diagnosis autis. Pada beberapa penelitian, diagnosis autis dapat ditegakkan pada usia 2-3 
tahun, walaupun sebagian besar pada kelompok usia $4-5$ tahun. ${ }^{12}$

Faktor perancu penelitian ini yaitu usia dan riwayat terapi perilaku selama $40 \mathrm{jam} / \mathrm{minggu}$ minimal tiga bulan tidak berhubungan dengan kelompok interaksi sosial aloof, pasif, dan aktif tetapi aneh (Tabel 1). Dengan demikian, faktor perancu tidak perlu diperhitungkan pada analisis selanjutnya. Kelompok interaksi sosial aloof, pasif, dan aktif tetapi aneh berhubungan dengan kapasitas fungsi intelektual rendah dan tinggi (Tabel 2). Karakteristik dan kompleksitas gejala klinis kelompok interaksi sosial aloof, pasif, dan aktif tetapi aneh berhubungan dengan tingkat kapasitas fungsi intelektual. ${ }^{3,9,15}$ Kumpulan gejala klinis gangguan bahasa/komunikasi, gangguan interaksi sosial, aktivitas atau perilaku yang bersifat stereotipik, ritual dan terbatas, gangguan imajinasi sosial, gangguan respons sensoris, serta gangguan motor sensoris yang kompleks dan berat, disertai dengan gangguan perilaku adaptif berat dan menetap, yang ditemukan pada kelompok interaksi sosial aloof, pasif, dan aktif tetapi aneh berhubungan dengan kapasitas fungsi intelektual rendah., ${ }^{9,11,12,19,20}$ Kompleksitas dan derajat berat ringan gejala klinis bervariasi dan berbeda untuk tiap kelompok interaksi sosial aloof, pasif, dan aktif tapi aneh. Bahkan pola, variasi, dan derajat berat ringan gejala klinis yang berbeda ditemukan pada anak autis dalam satu kelompok interaksi sosial yang sama. ${ }^{3,12,20}$

Uji statistik Kolmogorov Smirnov dua populasi tidak dapat dilanjutkan dengan partisi, sehingga tidak dapat dijelaskan hubungan kapasitas fungsi intelektual antara kelompok interaksi sosial aloof, pasif, dan aktif tetapi aneh. Bila kelompok interaksi sosial aloof tidak diikutsertakan karena jumlahnya sangat sedikit, pada uji statistik $\chi^{2}$ didapatkan nilai $\mathrm{p}<0,005$. Hasil ini menunjukkan bahwa kelompok interaksi sosial pasif berhubungan dengan kapasitas fungsi intelektual tinggi dan kelompok interaksi sosial aktif tapi aneh berhubungan dengan kapasitas fungsi intelektual rendah. Kemampuan bahasa verbal dan nonverbal kelompok interaksi sosial pasif dan aktif tapi aneh berkembang lebih baik, tetapi ditandai keterlambatan dan ciri aneh lainnya. ${ }^{3,918} \mathrm{Hal}$ tersebut dijelaskan oleh penulis lain yang melaporkan sebagian besar kelompok interaksi sosial aktif tapi aneh dan sebagian kelompok interaksi sosial pasif mempunyai kemampuan bahasa verbal yang baik (kapasitas fungsi intelektual baik). ${ }^{10}$ Tetapi jika berdasarkan kompleksitas dan derajat berat gejala klinis subjek penelitian, sebanyak $80 \%$ kelompok interaksi sosial aktif tetapi aneh termasuk kategori kapasitas fungsi intelektual rendah dan 52\% kelompok interaksi sosial pasif termasuk kategori kapasitas fungsi intelektual tinggi. Hal ini menunjukkan bahwa kelompok interaksi sosial aktif tetapi aneh mempunyai kumpulan gejala klinis yang lebih kompleks dan berat dibanding kelompok interaksi sosial pasif. Walaupun kelompok interaksi sosial pasif dan aktif tetapi aneh mempunyai kemampuan bahasa verbal dan nonverbal yang lebih baik, tetapi kompleksitas dan derajat berat gejala klinis yang ditemukan akan mempengaruhi kapasitas fungsi intelektual.

Kelemahan penelitian ini adalah populasi anak autis berasal dari dua lembaga pelayanan kesehatan. Populasi anak autis di lembaga kesehatan lain di kota Bandung yang mempunyai karakteristik dan sebaran kelompok interaksi sosial serta kapasitas fungsi intelektual tidak diketahui.

Simpulan penelitian ini, kelompok interaksi sosial aloof, pasif, dan aktif tetapi aneh anak autis berhubungan dengan kapasitas fungsi intelektual rendah dan tinggi.

\section{Daftar Pustaka}

1. Tidmarsh L, Volkmar FR. Diagnosis and epidemiology of autistic spectrum disorders. Can J Psychiatry. 2003;48:517-25.

2. Kabot S, Masi W, Segal M. Advances in the diagnosis and treatment of autism spectrum disorders. Professional Psychol Research Pract. 2003;34:26-33.

3. Pusponegoro HD. Autisme: bagaimana mengenal dan menegakkan diagnosis. Dalam: Trihono PP, Purnawati S, Syarif DR, Hegar B, Gunardi H, Oswari $\mathrm{H}$, dkk., penyunting. Hot topics in pediatrics II. Jakarta: Balai Penerbit FKUI; 2002. hlm. 47-62.

4. Solek P. Jumlah penderita autis melonjak sangat tajam. Pikiran Rakyat 11 November 2005; Seksi A-148 (Kolom 3).

5. Mauk JE, Reber M, Bathsaw ML. Autism and other pervasive developmental disorders. Dalam: Bathsaw ML, penyunting. Children with disabilities. Edisi ke-4. Baltimore: Brookes Publ Co; 2000. hlm. 449-70.

6. Tuchman R, Rapin I. Epilepsy in autism. Lancet Neurol. 2002;1:352-8. 
7. Ingersoll B, Schreibman L, Stahner A. Brief report: differential treatment outcomes for children with autistic spectrum disorder based on level of peer social avoidance. J Autism Dev Disord. 2001;31:343-54.

8. Joseph RM, Tager-Flushberg H, Lord C. Cognitive profiles and social-communicative functioning in children with autism spectrum disorder. J Child Psychol Psychiatry. 2002;43: 807-21.

9. Willemsen-Swinkels SHN, Buitelaar JK. The autistic spectrum: subgroups, boundaries, and treatment. Psychiatric Clin North Am. 2002;25: 811-36.

10. Waterhouse L, Morris R, Dunn M, Fein D, Feinstein C, Rapin I, et al. Diagnosis and classification in autism. J Autism Dev Disord. 1996;26: 59-86.

11. Pusponegoro HD, Solek P. Apakah anak kita autis? Bandung: Trikarsa Multi Media; 2007.

12. Baird G, Cass H, Slonims V. Diagnosis of autism. BMJ. 2003;327:488-93.

13. Newschaffer CJ, Curran LK. Autism: an emerging public health problem. Publ Health Rep. 2003; 118:393-9.
14. Tager-Flusberg H, Joseph RM. Identifying neurocognitive phenotypes in autism. Phil Trans R Soc Lond. 2003;277:131-43.

15. Tuchman R. Autism. 2003 (diunduh 17 Januari 2004). Tersedia dari: http://www.mdconsult.com.

16. Stevens MC, Fein DA, Dunn M, Allen D, Waterhouse L, Feinstein C, et al. Subgroups of children with autism by cluster analysis: a longitudinal examination. J Am Acad Child Adolesc Psychiatry. 2000;39:346-52.

17. Akshoomoff N, Lord C, Lincoln AJ, Courchesne $\mathrm{RY}$, Carper RA, Towsend $\mathrm{J}$, et al. Outcome classification of preschool children with autism spectrum disorders using MRI brain volumes. J Am Acad Child Adolesc Psychiatry. 2004;43:34957.

18. Wing L. The autistic spectrum: a guide for parents and professionals. London: Constable Co; 1998.

19. Ozonoff S, Dawson G, McPartland J. Understanding asperger's syndrome and high functioning autism. 2002 (diunduh 8 Juni 2006). Tersedia dari: http://www.guilford.com.

20. Jordan R. Autistic spectrum disorders: an introductory handbook for practitioners. London: David Fulton Publishers Ltd; 2001. 